www.nature.com/ja

\title{
A new cyclizidine analog-JBIR-102-from Saccharopolyspora sp. RL78 isolated from mangrove soil
}

\author{
Miho Izumikawa ${ }^{1}$, Takahiro Hosoya ${ }^{1}$, Motoki Takagi ${ }^{1}$ and Kazuo Shin-ya ${ }^{2}$ \\ The Journal of Antibiotics (2012) 65, 41-43; doi:10.1038/ja.2011.99; published online 2 November 2011
}

Keywords: cyclizidine; cytotoxicity; malignant pleural mesothelioma; mangrove soil; Saccharopolyspora

\begin{abstract}
Actinomycetes have always attracted attention as potential candidates warranting extensive investigation, because of their ability to produce pharmaceutically useful compounds. However, in recent years, the rate of the discovery of novel compounds from these bacteria has decreased significantly. ${ }^{1,2}$ As a consequence, it is now more important than ever to isolate actinomycetes from a wide variety of environmental sources and employ various isolation methods to obtain new bioactive compounds. In our efforts to isolate novel secondary metabolites, we have focused on mangrove soil as a rich source of diverse actinomycetes.
\end{abstract}

On the other hand, malignant pleural mesothelioma (MPM), which is associated with exposure to asbestos fibers, is an aggressive neoplasm developing from the pleura and is highly invasive to surrounding tissues. ${ }^{3-5}$ MPM has been demonstrated to be resistant to all conventional therapies, including chemotherapy, radiotherapy and surgery, and the prognosis of patients remains very poor. Consequently, it is a tumor that continues to be a difficult clinical problem. ${ }^{3-5}$ Therefore, development of novel therapeutic agents against MPM is strongly desired. In the course of our screening program for cytotoxic compounds against MPM cells, we have already discovered several novel anti-MPM compounds, namely, JBIR-23, ${ }^{6,7}$ the teleocidin analog JBIR-31, ${ }^{8}$ the aminocaprophenonealkaloid ficuseptamine $\mathrm{B},{ }^{9}$ the 1,1-dichlorocyclopropane-skeletoncontaining angucycline JBIR- $88,{ }^{10}$ the angucycline analogs JBIR-9093 and $-116,{ }^{11}$ the xanthoquinodin analogs JBIR-97-99, ${ }^{12}$ and the macrocyclic dilactone JBIR-101. ${ }^{13}$ As a result of further screening using MPM cells, we have discovered a new cyclizidine analog, termed JBIR-102 (1), from a culture of Saccharopolyspora sp. RL78, ${ }^{14}$ found in a mangrove soil sample (Figure 1a). This manuscript describes the fermentation, isolation, structural elucidation and, briefly, the biological activity of $\mathbf{1}$.
The strain Saccharopolyspora sp. RL78 was isolated from a mangrove soil sample collected in Nosoko, Ishigaki Island, Okinawa Prefecture, Japan. The strain was cultivated in 50-ml test tubes, each containing $15 \mathrm{ml}$ of a seed medium consisting of $1 \%$ starch (Kosokagaku, Tokyo, Japan), 1\% Polypepton (Nihon Pharmaceutical, Tokyo, Japan), 1\% molasses (Dai-Nippon Meiji Sugar, Tokyo, Japan) and 1\% meat extract (Extract Ehlrich, Wako Pure Chemical Industry, Osaka, Japan) before sterilization, with the $\mathrm{pH}$ adjusted to 7.2. The test tubes were shaken on a reciprocal shaker ( 320 r.p.m.) at $27^{\circ} \mathrm{C}$ for 2 days. Aliquots $(2.5 \mathrm{ml})$ of the broth were transferred to $500-\mathrm{ml}$ baffled Erlenmeyer flasks containing $100 \mathrm{ml}$ of a production medium containing $1 \%$ starch, $1 \%$ glucose, $1 \%$ glycerin (Nacalai Tesque, Kyoto, Japan), $0.5 \%$ Polypepton, $0.2 \%$ yeast extract (BD Biosciences, San Jose, CA, USA), 1\% corn steep liquor (Oriental Yeast, Tokyo, Japan), $0.1 \% \mathrm{NaCl}$ (Kanto Chemical, Tokyo, Japan), 0.32\% $\mathrm{CaCO}_{3}$ (Kozaki Pharmaceutical, Tokyo, Japan) and 1.9\% marine art SF-1 (Tomita Pharmaceutical, Tokushima, Japan) before sterilization, with the $\mathrm{pH}$ adjusted to 7.4. The flasks were cultured on a rotary shaker (180 r.p.m.) at $27^{\circ} \mathrm{C}$ for 5 days.

The mycelial cake collected from the fermentation broth (21) by centrifugation was extracted with $\mathrm{Me}_{2} \mathrm{CO}(400 \mathrm{ml})$. After concentrating in vacuo, the residual aqueous concentrate was extracted with EtOAc $(100 \mathrm{ml} \times 3)$. The separated organic layer was dried over $\mathrm{Na}_{2} \mathrm{SO}_{4}$ and concentrated in vacuo. The dried residue $(225 \mathrm{mg})$ was subjected to normal-phase medium-pressure liquid chromatography (Purif-Pack SI-30; Shoko Scientific, Yokohama, Japan), and was eluted stepwise by using a $\mathrm{CHCl}_{3}-\mathrm{MeOH}$ solvent system $(0,2,5$ and $10 \%$ $\mathrm{MeOH})$. The target eluate ( $5 \% \mathrm{MeOH}, 29 \mathrm{mg}$ ) was further purified by preparative reversed-phase high-performance liquid chromatography, using a CAPCELL PAK $\mathrm{C}_{18}$ MGII column $(5.0 \mu \mathrm{m}, 20$ i.d. $\times 150 \mathrm{~mm}$; Shiseido, Tokyo, Japan) with a 2996 photodiode array detector

${ }^{1}$ Biomedicinal Information Research Center (BIRC), Japan Biological Informatics Consortium (JBIC), Tokyo, Japan and ${ }^{2}$ Biomedicinal Information Research Center (BIRC), National Institute of Advanced Industrial Science and Technology (AIST), Tokyo, Japan

Correspondence: Dr K Shin-ya, Biomedicinal Information Research Center (BIRC), National Institute of Advanced Industrial Science and Technology (AIST), 2-4-7 Aomi, Koto-ku, Tokyo 135-0064, Japan.

E-mail: k-shinya@aist.go.jp

or Dr M Takagi, Biomedicinal Information Research Center (BIRC), Japan Biological Informatics Consortium (JBIC), 2-4-7 Aomi, Koto-ku, Tokyo 135-0064, Japan.

E-mail: motoki-takagi@aist.go.jp

Received 18 August 2011; revised 27 September 2011; accepted 29 September 2011; published online 2 November 2011 
a

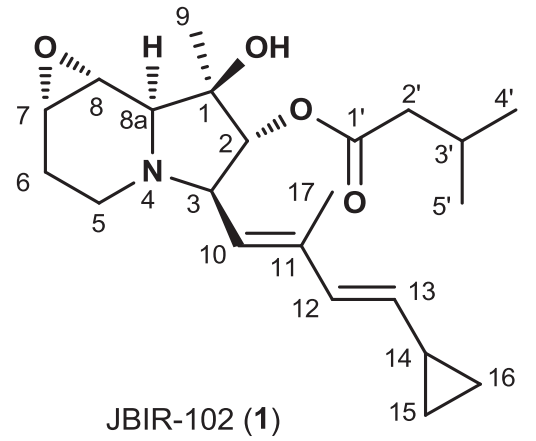

b

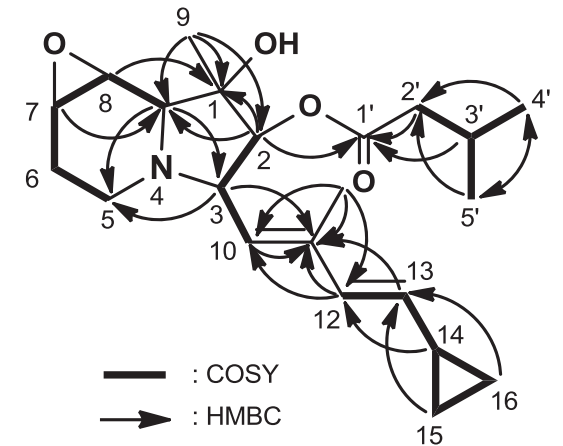

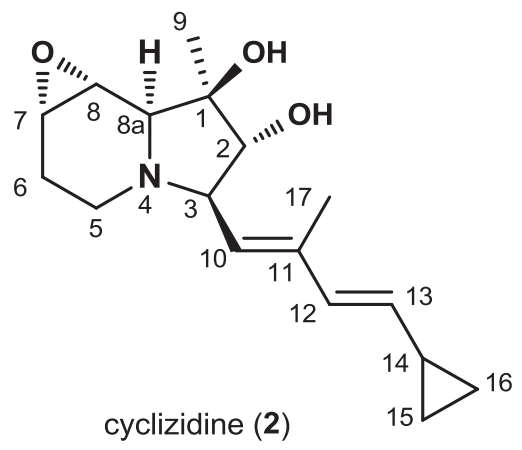

cyclizidine (2)
(Waters, Milford, MA, USA) and a 3100 mass detector (Waters) developed using $50 \%$ aqueous $\mathrm{MeOH}$, containing $0.1 \%$ formic acid (flow rate, $10 \mathrm{ml} \mathrm{min}^{-1}$ ) to yield 1 ( $3.4 \mathrm{mg}$, retention time $15.8 \mathrm{~min}$ ).

Compound 1 was obtained as a colorless amorphous solid $\left([\alpha]_{\mathrm{D}}^{25}\right.$ $-52.7^{\circ}$, c 0.1, in $\mathrm{MeOH}$; UV $\lambda_{\max }$ (ع) 243 (26590) $\mathrm{nm}$, in $\mathrm{MeOH})$. The molecular formula was determined by high-resolution electrospray ionization-MS to be $\mathrm{C}_{22} \mathrm{H}_{33} \mathrm{NO}_{4}$ (found: 376.2492 $[\mathrm{M}+\mathrm{H}]^{+}$, calcd: 376.2488$)$. The presence of hydroxy and ester groups were deduced from its IR spectrum $\left(v_{\max }(\mathrm{KBr}) 3420,1739\right.$, $\left.1294 \mathrm{~cm}^{-1}\right)$. The direct connectivity between protons and carbons was established by a heteronuclear single quantum coherence spectrum, and the tabulated ${ }^{13} \mathrm{C}$ and ${ }^{1} \mathrm{H}$ NMR spectroscopic data for $\mathbf{1}$ is shown in Table 1 . The structure of $\mathbf{1}$ was elucidated through the analysis of both DQF-COSY and constant time (CT)-HMBC ${ }^{15}$ spectra as follows.

Four substructures were demonstrated through analyses of the DQF-COSY spectrum, and the connectivity of those 4 units was established by CT-HMBC. The sequence from methylene protons $5-\mathrm{H}$ $\left(\delta_{\mathrm{H}} 2.63,1.87\right)$ to a methine proton $8 \mathrm{a}-\mathrm{H}\left(\delta_{\mathrm{H}} 2.17\right)$ through methylene protons $6-\mathrm{H}\left(\delta_{\mathrm{H}} 2.08\right)$ and oxymethine protons $7-\mathrm{H}\left(\delta_{\mathrm{H}}\right.$ 3.27) and $8-\mathrm{H}\left(\delta_{\mathrm{H}} 3.41\right)$, which are considered to exist in an epoxide functional group from their ${ }^{13} \mathrm{C}$ chemical shifts $\left(\delta_{\mathrm{C}} 52.3\right.$ and $\delta_{\mathrm{C}} 52.4$, respectively), was revealed by the DQF-COSY spectrum. A ${ }^{1} \mathrm{H}-{ }^{13} \mathrm{C}$ long-range coupling from the methine proton $8 \mathrm{a}-\mathrm{H}$ to a methylene carbon C-5 $\left(\delta_{\mathrm{C}} 44.0\right)$ helped to deduce that C-5 was bonded with C-8a $\left(\delta_{\mathrm{C}}\right.$ 72.2) through a heteroatom, which was determined to be a nitrogen atom from the ${ }^{13} \mathrm{C}$ chemical shift at C-5.

The proton spin systems of the oxymethine proton $2-\mathrm{H}\left(\delta_{\mathrm{H}} 4.99, \delta_{\mathrm{C}}\right.$ 79.9), an olefinic proton $10-\mathrm{H}\left(\delta_{\mathrm{H}} 5.26, \delta_{\mathrm{C}} 125.2\right)$, and a heteroatombonded methine proton $3-\mathrm{H}\left(\delta_{\mathrm{H}} 3.29, \delta_{\mathrm{C}} 63.9\right)$ were observed in the DQF-COSY spectrum. The ${ }^{1} \mathrm{H}-{ }^{13} \mathrm{C}$ long-range couplings from a singlet methyl proton $9-\mathrm{H}\left(\delta_{\mathrm{H}} 1.47\right)$ to a quaternary oxygenated
Table $1{ }^{13} \mathrm{C}(150 \mathrm{MHz})$ and ${ }^{1} \mathrm{H}(600 \mathrm{MHz}) \mathrm{NMR}$ data for 1 and 2

\begin{tabular}{|c|c|c|c|c|}
\hline \multirow[b]{2}{*}{ No. } & \multicolumn{2}{|r|}{1} & \multicolumn{2}{|r|}{2} \\
\hline & $\delta_{C}$ & $\begin{array}{l}\delta_{H} \\
\text { (multiplicity, J, in Hz) }\end{array}$ & $\delta_{C}$ & $\begin{array}{l}\delta_{H} \\
\text { (multiplicity, J, in Hz) }\end{array}$ \\
\hline 1 & 76.7 & & 75.9 & \\
\hline 2 & 79.9 & $4.99(\mathrm{~d}, 7.6)$ & 78.4 & $3.83(d, 7.0)$ \\
\hline 3 & 63.9 & $3.29(\mathrm{dd}, 8.5,7.6)$ & 65.3 & $3.09(\mathrm{dd}, 9.2,7.0)$ \\
\hline 5 & 44.0 & $\begin{array}{l}2.63(\mathrm{ddd}, 10.6,5.4,2.2) \\
1.87(\mathrm{dt}, 10.6,5.0)\end{array}$ & 44.4 & $\begin{array}{l}2.62(\mathrm{ddd}, 11.2,5.3,2.4) \\
1.86(\mathrm{~m})\end{array}$ \\
\hline 6 & 26.4 & $2.08(\mathrm{~m})$ & 26.1 & $2.07(\mathrm{~m})$ \\
\hline 7 & 52.3 & $3.27(\mathrm{~m})$ & 52.2 & $3.28(\mathrm{~m})$ \\
\hline 8 & 52.4 & $3.41(\mathrm{~d}, 4.1)$ & 52.5 & $3.45(d, 4.1)$ \\
\hline $8 a$ & 72.2 & $2.17(\mathrm{br} \mathrm{s})$ & 72.7 & $2.09(\mathrm{br} \mathrm{s})$ \\
\hline 9 & 23.4 & $1.47(\mathrm{~s})$ & 23.7 & $1.43(\mathrm{~s})$ \\
\hline 10 & 125.2 & $5.26(d, 8.5)$ & 125.1 & $5.36(d, 9.2)$ \\
\hline 11 & 139.4 & & 139.3 & \\
\hline 12 & 132.9 & $6.18(d, 15.6)$ & 133.3 & $6.26(d, 15.6)$ \\
\hline 13 & 135.0 & $5.24(\mathrm{dd}, 15.6,9.7)$ & 134.7 & $5.27(\mathrm{dd}, 15.6,8.8)$ \\
\hline 14 & 15.0 & $1.48(\mathrm{~m})$ & 15.0 & $1.48(\mathrm{~m})$ \\
\hline 15 & 7.6 & $0.78(\mathrm{dd}, 8.1,1.7)$ & 7.6 & $0.78(\mathrm{dd}, 7.8,1.8)$ \\
\hline 16 & 7.5 & $0.42(d d, 4.6,1.7)$ & 7.5 & $0.43(\mathrm{dd}, 4.4,1.8)$ \\
\hline 17 & 13.1 & $1.73(\mathrm{~s})$ & 13.3 & $1.78(\mathrm{~s})$ \\
\hline $1^{\prime}$ & 174.2 & & & \\
\hline $2^{\prime}$ & 44.1 & $\begin{array}{l}2.28(\mathrm{dd}, 14.8,7.3) \\
2.26(\mathrm{dd}, 14.8,7.0)\end{array}$ & & \\
\hline $3^{\prime}$ & 26.7 & $2.10(\mathrm{~m})$ & & \\
\hline $4^{\prime}$ & 22.9 & $0.97(d, 6.8)$ & & \\
\hline $5^{\prime}$ & 22.8 & $0.96(d, 6.8)$ & & \\
\hline
\end{tabular}

NMR spectra were obtained using the Varian NMR system 600 NB CL (Palo Alto, CA, USA) in $\mathrm{CD}_{3} \mathrm{OD}$, and the solvent peak was used as an internal standard ( $\delta_{\mathrm{H}} 3.35$ p.p.m. and $\delta_{\mathrm{C}}$ 49.0 p.p.m.) 
carbon $\mathrm{C}-1\left(\delta_{\mathrm{C}} 76.7\right)$, the oxymethine carbon $\mathrm{C}-2$ and the methine carbon C-8a, established the sequence from C-2 to C-8a through C-1. A long-range coupling from the methine proton $8 \mathrm{a}-\mathrm{H}$ to a methine carbon C-3 $\left(\delta_{\mathrm{C}} 63.9\right)$ determined a five-membered cyclic structure. Although the chemical shifts at C-3 and C-8a are greatly shifted downfield, these results indicate that this five-membered cyclic substructure is a pyrrolidine moiety. Taken together, 1 consists of a unique octahydroindolizine skeleton.

The sequence from an olefinic methine proton $12-\mathrm{H}\left(\delta_{\mathrm{H}} 6.18\right)$ to a methylene proton $16-\mathrm{H}\left(\delta_{\mathrm{H}} 0.42\right)$ through an olefinic proton $13-\mathrm{H}$ $\left(\delta_{\mathrm{H}} 5.24\right)$, a methine proton $14-\mathrm{H}\left(\delta_{\mathrm{H}} 1.48\right)$ and a methylene proton $15-\mathrm{H}\left(\delta_{\mathrm{H}} 0.78\right)$, was observed in the DQF-COSY spectrum. The ${ }^{1} \mathrm{H}-{ }^{1} \mathrm{H}$ spin coupling between $14-\mathrm{H}$ and $16-\mathrm{H}$ established a cyclopropane moiety. The ${ }^{1} \mathrm{H}-{ }^{13} \mathrm{C}$ long-range couplings from a methyl proton $17-\mathrm{H}\left(\delta_{\mathrm{H}} 1.73\right)$ to the olefinic methine carbons $\mathrm{C}-10\left(\delta_{\mathrm{C}} 125.2\right)$ and $\mathrm{C}-12\left(\delta_{\mathrm{C}} 132.9\right)$, and an olefinic quaternary carbon $\mathrm{C}-11\left(\delta_{\mathrm{C}} 139.4\right)$, revealed the connectivity between the vinylcyclopropane and the octahydroindolizine moieties through a vinyl methyl group. The geo-stereochemistry of this diene moiety was determined as $10 \mathrm{E}$ and $12 E$, respectively, according to the high-field-shifted chemical shift at a methyl carbon $\mathrm{C}-17\left(\delta_{\mathrm{C}} 13.1\right)$ and a $J_{12 \mathrm{H}, 13 \mathrm{H}}=15.6 \mathrm{~Hz}$.

A remaining substructure was elucidated as follows. The sequence from methylene protons $2^{\prime}-\mathrm{H}\left(\delta_{\mathrm{H}} 2.28,2.26\right)$ to the methyl proton $4^{\prime}-\mathrm{H}\left(\delta_{\mathrm{H}} 0.97\right)$ through a methine proton $3^{\prime}-\mathrm{H}\left(\delta_{\mathrm{H}} 2.10\right)$, which was ${ }^{1} \mathrm{H}$ spin coupled to a methyl proton $5^{\prime}-\mathrm{H}\left(\delta_{\mathrm{H}} 0.96\right)$, was determined by analysis of the DQF-COSY spectrum. In the HMBC spectrum, the methylene protons $2^{\prime}-\mathrm{H}$ and the oxymethine proton $2-\mathrm{H}$ were coupled to an ester carbonyl carbon C-1' $\left(\delta_{\mathrm{C}} 174.2\right)$. Thus, a 3-methylbutanoic acid moiety was shown to be substituted at the $\mathrm{C}-2$ position in the octahydroindolizine skeleton through an ester bond (Figure 1b).

To determine the absolute configuration of the cyclizidine moiety, 1 was reacted with $0.2 \mathrm{~N} \mathrm{NaOH}$ at $50^{\circ} \mathrm{C}$ for $1 \mathrm{~h}$ to yield cyclizidine (2, Figure 1a). The structure of $\mathbf{2}$ was confirmed with NMR spectroscopic data (Table 1). The results imply that the NMR assignments of $\mathbf{2}$ by Freer et al. ${ }^{16}$ are incorrect, and our data are identical to those reported by Leeper et al. ${ }^{17}$ The obtained 2 showed an optical rotation value $\left([\alpha]_{\mathrm{D}}^{25}-48.3, c 0.1, \mathrm{MeOH}\right)$ similar to the value $\left([\alpha]_{\mathrm{D}}^{25}-29.5, c 0.5\right.$, $\mathrm{MeOH})$ of 2 reported by Hanessian et al., ${ }^{18}$ who proposed the absolute configuration of $\mathbf{2}$ by total synthesis of ent-cyclizidine. Thus, the absolute configuration of $\mathbf{1}$ was deduced to be the same as that of 2 (Figure 1a). Although an acetylcyclizidine has been reported, ${ }^{16}$ this is the first report of an isobutyl ester derivative of cyclizidine.

Cytotoxic activities against human MPM ACC-MESO-1 cells ${ }^{19}$ and human cervical carcinoma $\mathrm{HeLa}$ cells were determined by a colorimetric assay by using 2-(2-methoxy-4-nitrophenyl)-3-(4nitrophenyl)-5-(2,4-disulfophenyl)-2H-tetrazolium monosodium salt (WST-8, Cell Counting Kit; Dojiindo, Kumamoto, Japan) for $48 \mathrm{~h}$. Compounds $\mathbf{1}$ and $\mathbf{2}$ exhibited cytotoxic activities against
ACC-MESO- 1 with IC $_{50}$ values of $39 \mu \mathrm{m}$ and $32 \mu \mathrm{m}$ and against HeLa cells with $\mathrm{IC}_{50}$ values of $29 \mu \mathrm{m}$ and $16 \mu \mathrm{M}$, respectively.

\section{ACKNOWLEDGEMENTS}

This work was supported by a grant from the New Energy and Industrial Technology Department Organization (NEDO) of Japan and a Grant-in-Aid for Scientific Research (23380067 to KS) from the Japan Society for the Promotion of Science (JSPS). We thank Mr Akihiko Kanamoto, OP BIO FACTORY Co. Ltd, for his help in the collection of the seaweed sample.

1 Berdy, J. Bioactive microbial metabolites-a personal view. J. Antibiot. 58, 1-26 (2005).

2 Li, J. W. H. \& Vederas, J. C. Drug discovery and natural products: end of an era or an endless frontier? Science 325, 161-165 (2009).

3 Carbone, M., Kratzke, R. A. \& Testa, J. R. The pathogenesis of mesothelioma. Semin. Oncol. 29, 2-17 (2002).

4 Mossman, B. T., Kamp, D. W. \& Weitzman, S. A. Mechanisms of carcinogenesis and clinical features of asbestos-associated cancers. Cancer Invest. 14, 466-480 (1996).

5 Sekido, Y. Genomic abnormalities and signal transduction dysregulation in malignant mesothelioma cells. Cancer Sci. 101, 1-6 (2010)

6 Motohashi, K., Hwang, J.- H., Sekido, Y., Takagi, M. \& Shin-ya, K. JBIR-23 and -24, novel anticancer agents from Streptomyces sp. AK-AB27. Org. Lett. 11, 285-288 (2009).

7 Hwang, J.- H., Takagi, M., Murakami, H., Sekido, Y. \& Shin-ya, K. Induction of tubulin polymerization and apoptosis in malignant mesothelioma cells by a new compound JBIR-23. Cancer Lett. 300, 189-196 (2011)

8 Izumikawa, M., Khan, S. T., Komaki, H., Takagi, M. \& Shin-ya, K. JBIR-31, a new teleocidin analog, produced by salt-requiring Streptomyces sp. NBRC 105896 isolated from a marine sponge. J. Antibiot. 63, 33-36 (2010).

9 Ueda, J., Takagi, M. \& Shin-ya, K. Aminocaprophenone- and pyrrolidine-type alkaloids from the leaves of Ficus septica. J. Nat. Prod. 72, 2181-2183 (2009).

10 Motohashi, K., Takagi, M., Yamamura, H., Hayakawa, M. \& Shin-ya, K. A new angucycline and a new butenolide isolated from lichen-derived Streptomyces spp. J. Antibiot. 63, 545-548 (2010).

11 Ueda, J. et al. New angucycline $C$-glycosides from Streptomyces sp. RI33. J. Antibiot. 64, 367-372 (2011).

12 Ueda, J., Takagi, M. \& Shin-ya, K. New xanthoquinodin-like compounds, JBIR-97, -98 and -99, obtained from marine sponge-derived fungus Tritirachium sp. SpB081112MEf2. J. Antibiot. 63, 615-618 (2010).

13 Izumikawa, M., Takagi, M. \& Shin-ya, K. Isolation of a novel macrocyclic dilactoneJBIR-101-from Promicromonospora sp. RL26. J. Antibiot 64, 689-691 (2011).

14 Takagi, M. \& Shin-ya, K. New species of actinomycetes do not always produce new compounds with high frequency. J. Antibiot. (e-pub ahead of print 27 July 2011; doi:10.1038/ja.2011.66).

15 Furihata, K. \& Seto, H. Constant time HMBC (CT-HMBC), a new HMBC technique useful for improving separation of cross peaks. Tetrahedron Lett. 39, 7337-7340 (1998).

16 Freer, A. A., Gardner, D., Greatbanks, D., Polyser, J. P. \& Sim, G. A. Structure of cyclizidine (antibiotic M146791): X-ray crystal structure of an indolizidinediol metabolite bearing a unique cyclopropyl side-chain. J. Chem. Soc., Chem. Commun. 1160-1162 (1982).

17 Leeper, F. J., Padmanabhan, P., Kirby, G. W. \& Sheldrake, G. N. Biosynthesis of the indolizidine alkaloid, cyclizidine. J. Chem. Soc., Chem. Commun. 505-506 (1987).

18 Hanessian, S., Soma, U., Dorich, S. \& Deschênes-Simard, B. Total synthesis of (+)-entcyclizidine: absolute configurational confirmation of antibiotic M146791. Org. Lett. 13, 1048-1051 (2011).

19 Usami, N. et al. Establishment and characterization of four malignant pleural mesothelioma cell lines from Japanese patients. Cancer Sci. 97, 387-394 (2006). 